\title{
Chemoselective, Scalable Nickel-Electrocatalytic $O$-Arylation of Alcohols
}

\section{Authors:}

Hai-Jun Zhang, ${ }^{[1]}$ Longrui Chen, ${ }^{[1]}$ Martins S. Oderinde, ${ }^{[2]}$ Jacob T. Edwards, ${ }^{[3]}$ Yu Kawamata, ${ }^{[1]}$ and Phil S. Baran*[1]

\section{Affiliations:}

[1] Department of Chemistry The Scripps Research Institute 10550 North Torrey Pines Road, La Jolla, CA 92037, USA.

[2] Department of Discovery Synthesis Bristol Myers Squibb Research \& Early Development Princeton, NJ 08540, USA.

[3] Bristol Myers Squibb Redwood City, CA 94063, USA.

Correspondence to: pbaran@scripps.edu

\begin{abstract}
:
The formation of aryl-alkyl ether bonds through cross coupling of alcohols with aryl halides represents a useful strategic departure from classical $\mathrm{S}_{\mathrm{N}} 2$ methods. Numerous tactics relying on $\mathrm{Pd}-, \mathrm{Cu}-$, and Ni-based catalytic systems have emerged over the past several years. Herein we disclose a Ni-catalyzed electrochemically driven protocol to achieve this useful transformation with a broad substrate scope in an operationally simple way. This electrochemical method does not require strong base, exogenous expensive transition metal catalysts (e.g. Ir, Ru), and can easily be scaled up in either a batch or flow setting. Interestingly, e-etherification exhibits an enhanced substrate scope over the mechanistically related photochemical variant as it tolerates tertiary amine functional groups in the alcohol nucleophile.
\end{abstract}

\section{Main text:}

Aryl-alkyl ether bond construction is one of the most often-employed transformations in the pharmaceutical industry. ${ }^{[1]}$ Such linkages are often forged using classical substitution chemistry 
such as $\mathrm{S}_{\mathrm{N}} 2$ displacement represented by Williamson ether synthesis ${ }^{[2]}$ and Mitsunobu reaction ${ }^{[3]}$ or nucleophilic aromatic substitution. ${ }^{[4]}$ The synthesis of BET inhibitor intermediate 1 (Figure 1) is emblematic of this approach wherein a phenol $\mathbf{4}$ is alkylated with an alkyl halide $\mathbf{3}$, followed by the second alkylation to attach the piperazine unit $\mathbf{2}$ and Miyaura borylation for installing the requisite $\mathrm{C}-\mathrm{B}$ bond.$^{[5]}$ Although the approach is quite straightforward, step-count and overall yield are not satisfactory. The explosive success of transition-metal catalyzed N-arylation methods ${ }^{[6]}$

\section{$\mathrm{S}_{\mathrm{N}} 2$ vs coupling: coupling as modular approach for aryl alkyl ethers}
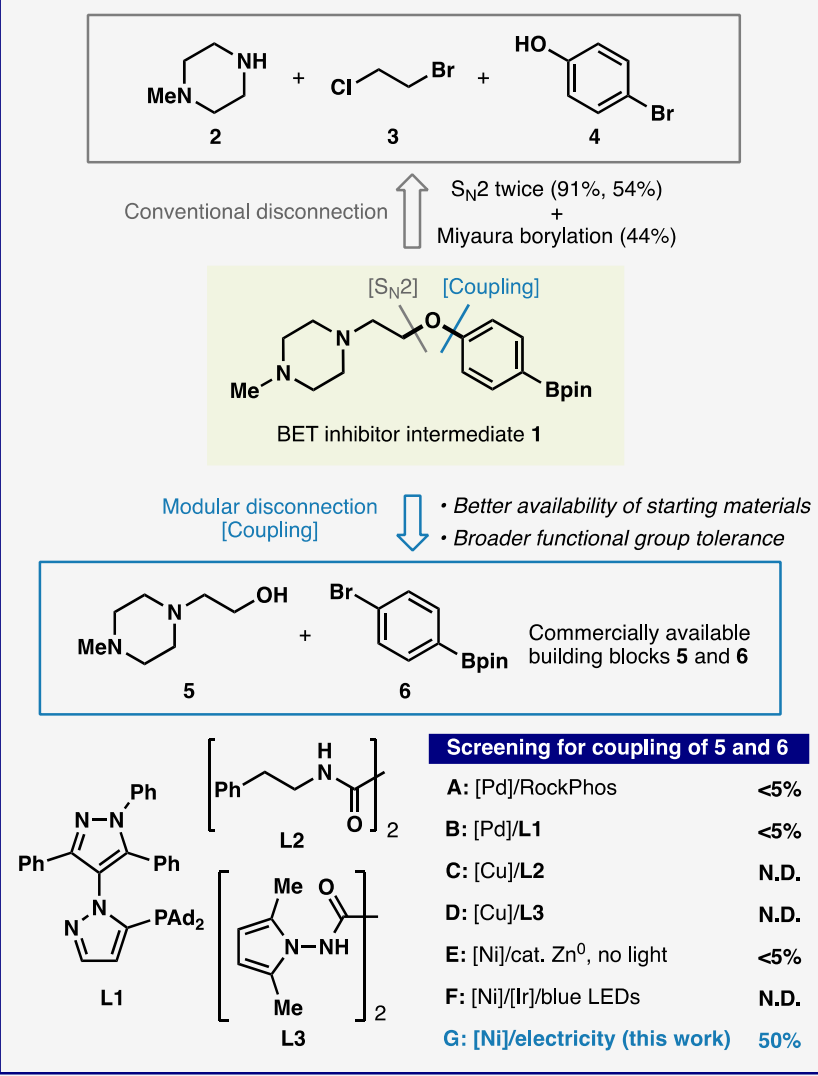

Figure 1. Comparison between $\mathrm{S}_{\mathrm{N}} 2$-based strategies and coupling approach in the synthesis of BET inhibitor intermediate 1 . Whereas the $\mathrm{S}_{\mathrm{N}} 2$ approach suffers from low overall yield and known methods (A-F) for ether cross coupling fail, e-etherification proceeds smoothly. The yields shown in conditions A-G are crude ${ }^{1} \mathrm{H}-\mathrm{NMR}$ yields. based on Ni such as conditions $\mathbf{E}^{[13]}$ and photochemical conditions $\mathbf{F}^{[11 \mathrm{a}]}$ also failed to deliver $\mathbf{1}$ presumably due to their incompatibility with the tertiary amine motif, which is ubiquitous in pharmaceutical molecules. This study reports the development of a Ni-catalyzed electrochemical etherification (e-etherification) that can succeed in this demanding context (conditions $\mathbf{G}$ ) without recourse to specialized experimental setups or expensive metals and ligands. This electrochemical

an analogous union of alcohols and aryl halides ${ }^{[7]}$ by using $\mathrm{Pd},{ }^{[8]} \mathrm{Cu},{ }^{[9]}$ and $\mathrm{Ni}^{[10-13]}$ catalysis. This coupling strategy is an attractive alternative to classic $\mathrm{S}_{\mathrm{N}} 2$-based retrosynthesis; the aryl halide building blocks are often easier to access, and the conditions employed can sometimes be more chemoselective. Continuing with this case study, the coupling approach (Figure 1) requires building blocks 5 and $\mathbf{6}$, which are both commercially available. However, the key C-O bond formation was found to be challenging even under the latest state-of-theart conditions. For example, catalytic reactions based on $\operatorname{Pd}$ (conditions $\mathbf{A}^{[8 i]}$ and $\mathbf{B}^{[8 \mathrm{~h}]}$ ) and $\mathrm{Cu}$ (conditions $\mathbf{C}^{[9 \mathrm{n}]}$ and $\mathbf{D}^{[90]}$ ) in combination with recently described ligands struggled to forge the $\mathrm{C}-\mathrm{O}$ bond. Methods 
method exhibits a broad substrate scope, high chemoselectivity, and represents an economically viable and sustainable means to conduct such etherification reactions on scale.

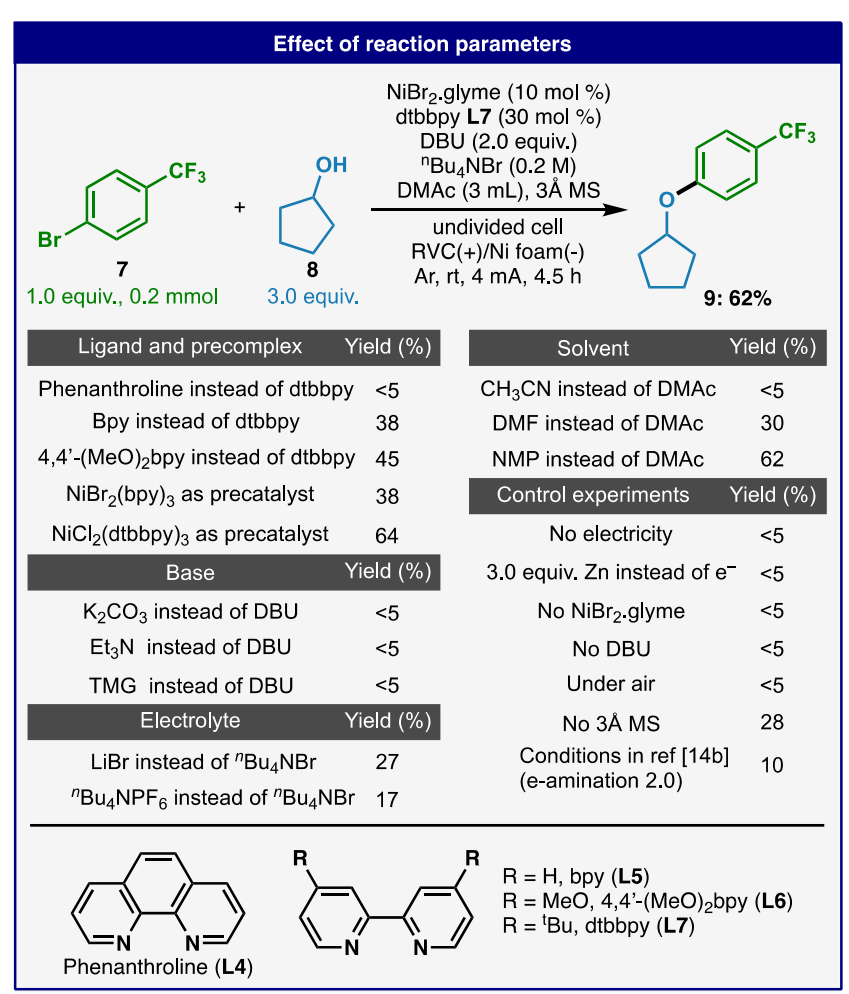

Figure 2. Effects of various reaction parameters. Yields determined by gas chromatography.
The development and optimization of the $\mathrm{Ni}-$ catalyzed aryl halide etherification commenced with the lessons learned during studies on the analogous e-amination reaction, ${ }^{[14]}$ and employed bromoarene 7 and cyclopentanol 8 to access ether 9 (Figure 2). Prior detailed mechanistic and optimization studies for e-amination pointed to the importance of the ligand/Ni ratio, the use of DBU as a base, and ${ }^{n} \mathrm{Bu}_{4} \mathrm{NBr}$ as the electrolyte. In the case of etherification, those variables proved critical; however the maximum yield obtained using those conditions was only $10 \%$ yield. Remarkably, by simply changing the ligand from $\mathbf{L 5}$ to $\mathbf{L} 7$ and adding $3 \AA$ molecular sieves the yield improved to $62 \%$. Control experiments reinforced several important aspects of this reaction. First, electricity is necessary for the reaction to proceed (shutting off electrical current immediately halts the reaction). Second, the $\mathrm{Ni}$-catalyst is playing a crucial role for the product formation under basic conditions as the omission of $\mathrm{Ni}$ or DBU resulted in no ether formation. Third, replacement of electricity with a chemical reductant ( $\mathrm{Zn}$ powder) resulted in no product formation. These results are consistent with chemical, ${ }^{[15-16]}$ photochemical, ${ }^{[11 \mathrm{a}, 11 \mathrm{c}, 17-19]}$ and electrochemical ${ }^{[14 \mathrm{~b}]}$ mechanistic studies, consistent with the Ni-catalytic cycle being driven in a paired electrolysis fashion, ${ }^{[14,20]}$ requiring both oxidation and reduction. Although the reaction is sensitive to air, a simple Arballoon is used and no laborious procedures for degassing (or a glovebox) are needed. As described below, during scale-up a modified procedure can be used in flow that does tolerate air. DMA and NMP were found to be ideal solvents as they render reactions good solubility and have high conductivity. Finally, the use of a Ni-L7 precatalyst, $\mathrm{NiCl}_{2}(\mathrm{dtbbpy})_{3}$, improved the operational 
simplicity of the reaction without any reduction in yield (64\%). This readily prepared, bench-stable, and non-hygroscopic Ni-precatalyst (see SI for preparation) was utilized for the remainder of these studies.

Table 1 provides a snapshot of the broad scope of e-etherification with 41 out of $>80$ examples shown (see SI for full scope and limitations). The use of a relatively mild organic base DBU and room temperature conditions enabled a range of functional groups to be tolerated. For example, reductively labile $\mathrm{C}$ - $\mathrm{X}$ bonds $(\mathrm{X}=\mathrm{Br}, \mathrm{Cl}, \mathrm{F})$ and fluoroethers $(\mathbf{1 0 - 2 2}, \mathbf{3 9}, \mathbf{4 0}, \mathbf{4 1}, \mathbf{4 7} 48)$, ester (49) and ketones $(42,50)$ were well tolerated. Even an aromatic aldehyde $(43)$ was compatible in this reaction. In addition, oxidatively labile groups such as $3^{\circ}$ amines (26), electron-rich arenes $(\mathbf{2 3}, \mathbf{2 4})$ as well as heterocycles $(\mathbf{2 7 - 3 3}, \mathbf{4 5}, \mathbf{4 6})$, and C-B bond $(\mathbf{3 8}, \mathbf{4 1 - 5 0})$ were found intact. Sensitive or polar (N-H containing) motifs such as carbamates (18, 27, 31-33), Lewis-basic heterocycles (34, 35, 40, 44), amides $(25,26)$ and ketals $(28,37,49)$ showed no complications under the reaction conditions. Regarding the scope of alcohol coupling partner, both primary and secondary alcohol were compatible whereas tertiary alcohols were found to be inefficient. The efficient coupling of nucleosides and polyfunctionalized fragments is also notable (36-37). Taken together, this eetherification method provides an easy access to small molecules and building blocks for pharmaceutical drug discovery efforts. 


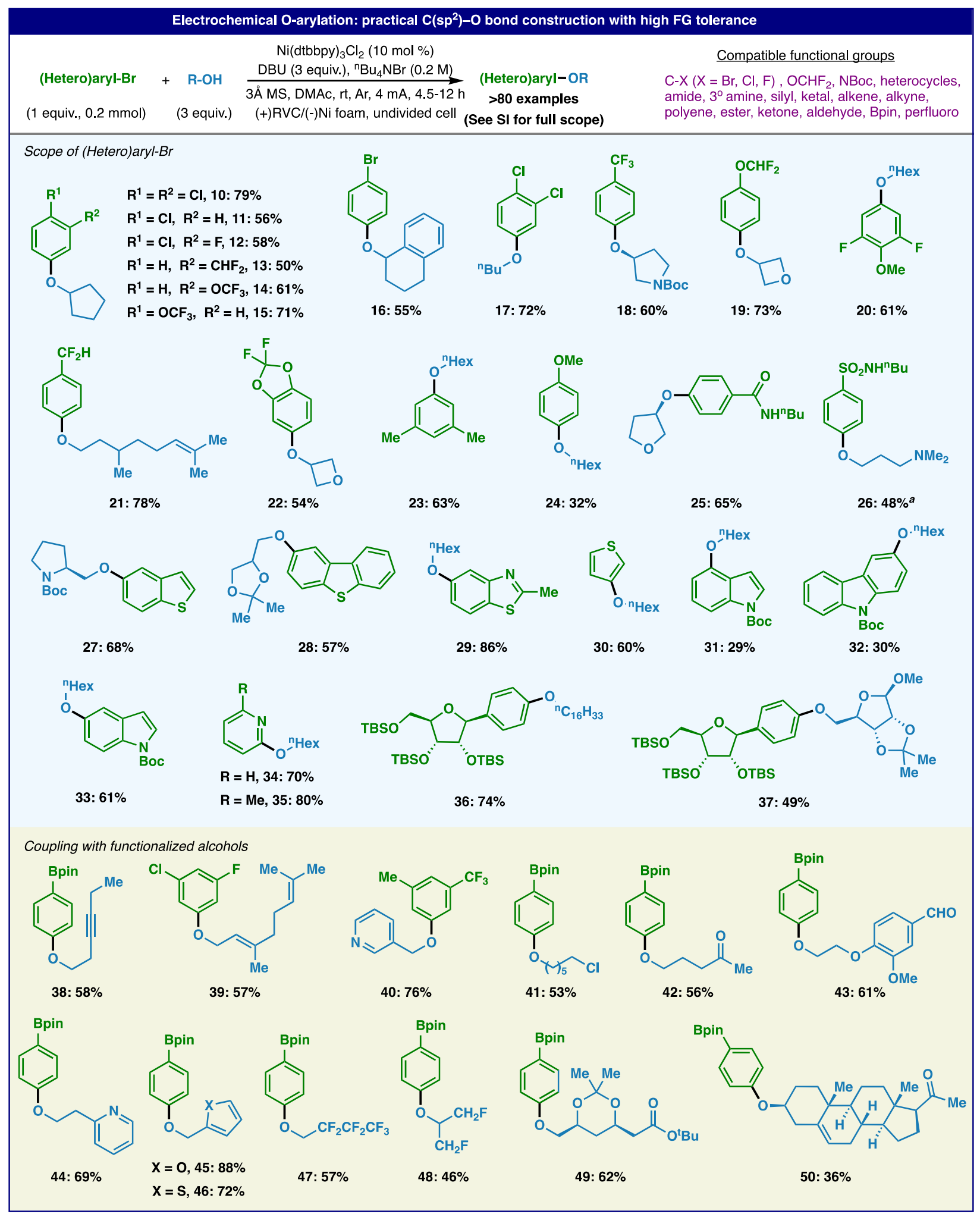

Table 1. Selected scope of aryl bromides and alcohols (See SI for the full scope). All yields are isolated yields. [a] Using 6 equiv. of alcohol. 
Table 2 illustrates the synthesis of known ether products wherein conventional strategies were used in prior routes and also compares the e-etherification with known $\mathrm{Cu}, \mathrm{Pd}$, and $\mathrm{Ir} / \mathrm{Ni}$-based methods. The room temperature conditions of e-etherification avoids the use of highly basic metal alkoxides or insoluble inorganic bases, does not require rigorous deoxygenation procedures (simple air/argon exchange), and deletes precious metal catalysts. With regards to the prior routes to access such valuable intermediates, a strong reliance on $\mathrm{S}_{\mathrm{N}} 2$ and Mitsunobu chemistry along with Miyaura borylation leads to lengthy and low yielding routes. In the case of oxetane-containing structures such as $\mathbf{5 4}$ and 56, recourse to oxetane ring synthesis after ether bond formation is required (See SI for full summary of all past routes). Most notably, e-etherification succeeded in delivering ether products even with substrates on which analogous photochemical conditions did not work $(\mathbf{6 5 - 6 7}, \mathbf{2 6})$, demonstrating broader substrate scope that can be achieved by the electrochemical means. The unique success of e-etherification in such instances despite having mechanistic similarities to the photochemical variant might be ascribed to the more strongly oxidizing conditions that favor reoxidation of $\mathrm{Ni}$ (II) to $\mathrm{Ni}$ (III) versus tertiary amine oxidation. 
In addition to superior functional group tolerance to other methods, another important advantage of the current method stems from the ease with which scale-up can be accomplished. As depicted in Figure 3, the reaction conditions can be used for batch preparation of 69, a valuable building block for drug discovery using a commercial potentiostat from $2 \mathrm{mmol}$ to $60 \mathrm{mmol}$. Most significantly, adaptation to flow carries several salient advantages as exemplified for the decagram synthesis of ether 71. These include: (1) the use of simple inexpensive carbon felt electrodes; (2) no precautions to remove air; and (3) no need for exclusion of water using molecular sieves. As

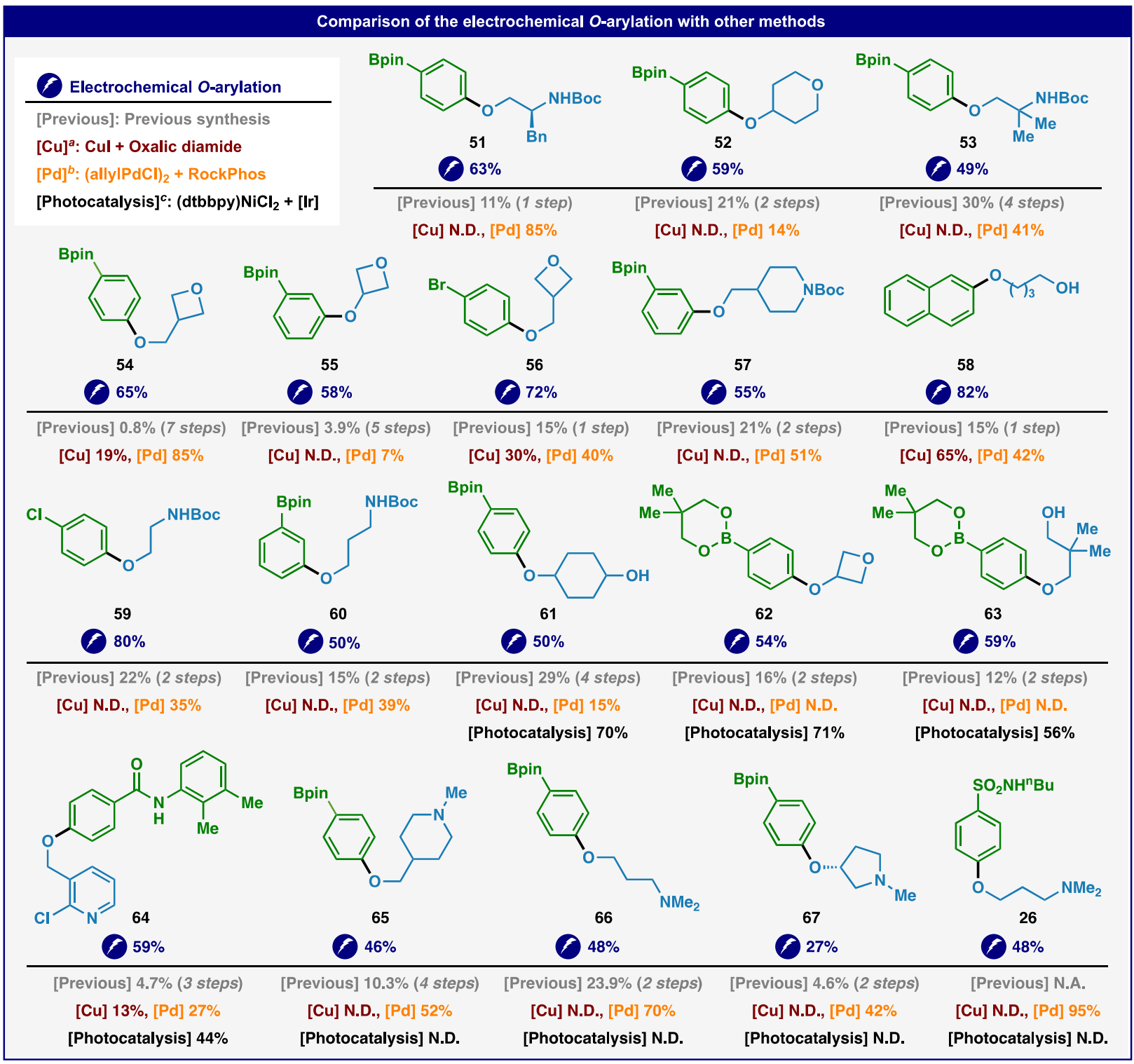

Table 2. Improved access to various compounds by electrochemical $O$-arylation. Yields under other coupling conditions are also shown. See SI for the experimental conditions for each compound. The yields of electrochemical $O$-arylation are isolated yields. [a] Ref. [9n], crude ${ }^{1} \mathrm{H}-N M R$ yields. [b] Ref. [8i], crude ${ }^{1} \mathrm{H}-\mathrm{NMR}$ yields. [c] Ref. [11a], isolated yields. 
such, a $100 \mathrm{mmol}$ run on aryl bromide $\mathbf{7 0}$ can be completed in only 16 hours to deliver $70 \%$ isolated yield of 71 .

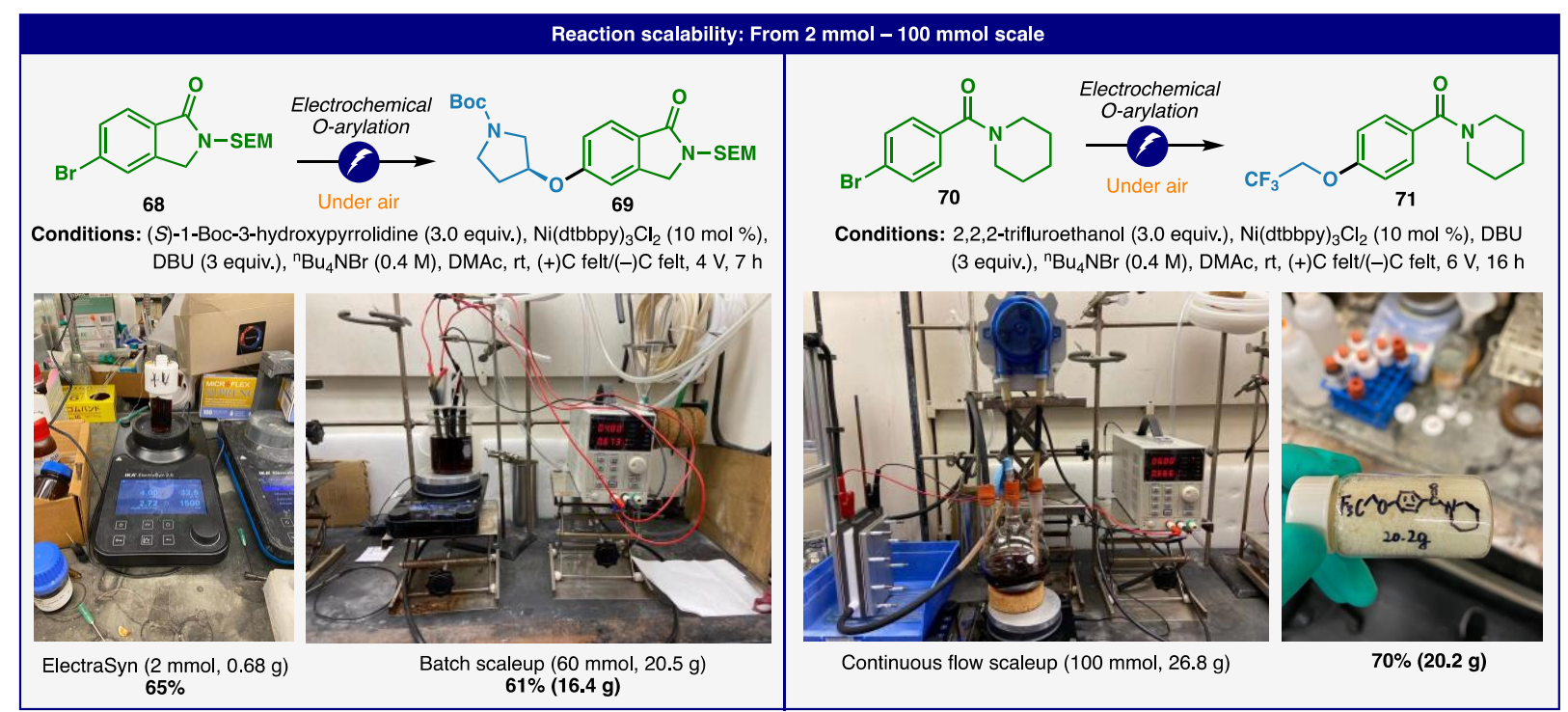

Figure 3. Electrochemical O-arylation performed on various scale from $2 \mathrm{mmol}$ to $100 \mathrm{mmol}$. All yields are isolated yields.

In conclusion, an electrochemical method for the etherification of aryl bromides has been developed that exhibits a broad substrate scope tolerating numerous sensitive functionalities. To the best of our knowledge, this work exhibits the widest substrate scope among all the related methods published thus far. It offers a useful alternative to classic $\mathrm{S}_{\mathrm{N}}$ 2-based methods for ether synthesis, and represents a practical, scalable, and inexpensive gateway to such structures that does not rely on precious metal additives or complex ligands.

\section{Associated content:}

Supporting Information containing experimental procedures and characterizations is available.

\section{Acknowledgement:}

This project was financially supported by National Science Foundation Center for Synthetic Organic Electrochemistry CHE-2002158, National Institutes of Health grant GM-118176, and SIOC fellowship (postdoctoral fellowship to H.-J.Z.). We thank Dr. D.-H. Huang and Dr. L. Pasternack (Scripps Research) for assistance with NMR spectroscopy, to Dr. J. Chen, B. Sanchez, and E. Sturgell (Scripps Automated Synthesis Facility) for assistance with HRMS. 


\section{References:}

[1] a) S. Enthaler, A. Company, Chem. Soc. Rev. 2011, 40, 4912 - 4924; b) S. D. Roughley, A. M. Jordan, J. Med. Chem. 2011, 54, 3451 - 3479; c) D.G. Brown, J. Boström, J. Med. Chem. 2016, 59, 4443 - 4458; d) G. Evano, J. J. Wang, A. Nitelet, Org. Chem. Front. 2017, 4, 2480 -2499 .

[2] E. Fuhrmann, J. Talbiersky, Org. Process Res. Dev. 2005, 9, $206-211$.

[3] K. C. K. Swamy, N. N. B. Kumar, E. Balaraman, K. V. P. Kumar, Chem. Rev. 2009, 109, $2551-2651$.

[4] "Nucleophilic Aromatic Substitution": S. Caron, A. Ghosh, Practical Synthetic Organic Chemistry, Wiley, Hoboken, 2011, pp. 237 - 253.

[5] M. J. Meyers, F. M. Sverdrup, T. Caldwell, J. Oliva, WO 2020132004, 2020.

[6] Selected reviews: a) C. Fischer, B. Koenig, Beilstein J. Org. Chem. 2011, 7, 59 - 74; b) I. P. Beletskaya, A. V. Cheprakov, Organometallics 2012, 31, 7753 - 7808; c) P. Ruiz-Castillo, S. L. Buchwald, Chem. Rev. 2016, 116, $12564-12649$.

[7] Selected reviews of the metal-catalyzed C-O cross-coupling: a) K. Keerthi Krishnan, S. M. Ujwaldev, K. S. Sindhu, G. Anilkumar, Tetrahedron 2016, 72, 7393 - 7407; b) S. Bhunia, G. G. Pawar, S. V. Kumar, Y. W. Jiang, D. Ma, Angew. Chem. Int. Ed. 2017, 56, 16136 - 1679; Angew. Chem. 2017, 129, 16352 - 16397.

[8] Selected examples of Pd-catalyzed $O$-arylation of alcohols: a) G. Mann, J. F. Hartwig, J. Am. Chem. Soc. 1996, 118, 13109 - 13110; b) M. Palucki, J. P. Wolfe, S. L. Buchwald, J. Am. Chem. Soc. 1997, 119, 3395 - 3396; c) G. Mann, J. F. Hartwig, J. Org. Chem. 1997, 62, 5413 - 5418; d) K. E. Torraca, X. Huang, C. A. Parrish, S. L. Buchwald, J. Am. Chem. Soc. 2001, 123, 10770 - 10771; e) A. V. Vorogushin, X. Huang, S. L. Buchwald, J. Am. Chem. Soc. 2005, 127, 8146 - 8149; f) G. J. Withbroe, R. A. Singer, J. E. Sieser, Org. Process Res. Dev. 2008, 12, 480-489; g) E. J. Milton, J. A. Fuentes, M. L. Clarke, Org. Biomol. Chem. 2009, 7, 2645 - 2678; h) S. Gowrisankar, A. G. Sergeev, P. Anbarasan, A. Spannenberg, H. Neumann, M. Beller, J. Am. Chem. Soc. 2010, 132, 11592 - 11598; i) X. Wu, B. P. Fors, S. L. Buchwald, Angew. Chem. Int. Ed. 2011, 50, 9943 - 9947; Angew. Chem. 2011, 123, 10117 - 10121; j) S. Gowrisankar, H. Neumann, M. Beller, Chem. Eur. J. 2012, 18, 2498 - 2502; k) P. E. Maligres, J. Li, S. W. Krska, J. D. Schreier, I. T. Raheem, Angew. Chem. Int. Ed. 2012, 51, 9071 - 9074; Angew. Chem. 2012, 124, 9205 - 9208; 1) N. C. Bruno, S. L. Buchwald, Org. Lett. 2013, 15, 
2876 - 2879; m) C. W. Cheung, S. L. Buchwald, Org. Lett. 2013, 15, 3998 - 4001; n) T. M. Rangarajan, R. Singh, R. Brahma, K. Devi, R. P. Singh, A. K. Prasad, Chem. Eur. J. 2014, 20, 14218 - 14225; o) T. M. Rangarajan, R. Brahma, Ayushee, A. K. Prasad, A. K. Verma, R. P. Singh, Tetrahedron Lett. 2015, 56, 2234 - 2237; p) R. S. Sawatzky, B. K. V. Hargreaves, M. Stradiotto, Eur. J. Org. Chem. 2016, 2444 - 2449; q) H. Zhang, P. Ruiz-Castillo, S. L. Buchwald, Org. Lett. 2018, 20, 1580 - 1583; r) S. D. Laffoon, V. S. Chan, M. G. Fickes, B. Kotecki, A. R. Ickes, J. Henle, J. G. Napolitano, T. S. Franczyk, T. B. Dunn, D. M. Barnes, A. R. Haight, R. F. Henry, S. Shekhar, ACS Catal. 2019, 9, 11691 - 11708; s) H. Zhang, P. Ruiz-Castillo, A. W. Schuppe, S. L. Buchwald, Org. Lett. 2020, 22, 5369 - 5374; t) M. S. Mikus, C. Sanchez, C. Fridrich, J. F. Larrow, Adv. Synth. Catal. 2020, 362, 430 - 436.

[9] Selected examples of Cu-catalyzed $O$-arylation of alcohols: a) M. Wolter, G. Nordmann, G. E. Job, S. L. Buchwald, Org. Lett. 2002, 4, 973 - 976; b) A. Shafir, P. A. Lichtor, S. L. Buchwald, J. Am. Chem. Soc. 2007, 129, 3490 - 3491; c) H. Zhang, D. Ma, W. Cao, Synlett. 2007, 2, 243 - 246; d) R. A. Altman, A. Shafir, A. Choi, P. A. Lichtor, S. L. Buchwald, J. Org. Chem. 2008, 73, 284 - 286; e) J. Niu, H. Zhou, Z. Li, J. Xu, S. Hu, J. Org. Chem. 2008, 73, 7814 - 7817; f) A. B. Naidu, G. Sekar, Tetrahedron Lett. 2008, 49, 3147-3151. g) A. B. Naidu, E. A. Jaseer, G. Sekar, J. Org. Chem. 2009, 74, 3675 - 3679; h) J. Niu, P. Guo, J. Kang, Z. Li, J. Xu, S. Hu, J. Org. Chem. 2009, 74, 5075 - 5078; i) D. Maiti, Chem. Commun. 2011, 47, 8340 - 8342; j) J. Huang, Y. Chen, J. Chan, M. L. Ronk, R. D. Larsen, M. M. Faul, Synlett. 2011, 10, 1419 - 1422; k) Y, Guo, X.-M. Fan, M. Nie, H.-W. Liu, D.-H. Liao, X.-D. Pan, Y.F. Ji, Eur. J. Org. Chem. 2015, $4744-4755$; 1) Y. Zheng, W. Zou, L. Luo, J. Chen, S. Lin, Q. Sun, $R S C$ Adv. 2015, 5, 66104-66108; m) H. Sugata, T. Tsubogo, Y. Kino, H. Uchiro, Tetrahedron Lett. 2017, 58, 1015 - 1019; n) Z. Chen, Y. Jiang, L. Zhang, Y. Guo, D. Ma, J. Am. Chem. Soc. 2019, 141, 3541 - 3549; o) R. Ray, J. F. Hartwig, Angew. Chem. Int. Ed. 2021, 60, 8203 - 8211; Angew. Chem. 2021, 133, 8284 - 8292.

[10] A recent review on Ni-catalyzed C-heteroatom cross-coupling reactions: C. Zhu, H. Yue, J. Jia, M. Rueping, Angew. Chem. Int. Ed. 2021, DOI: 10.1002/ange.202013852.

[11] Selected examples of Ni-catalyzed $O$-arylation of alcohols using photocatalysis: a) J. A. Terrett, J. D. Cuthbertson, V. W. Shurtleff, D. W. C. MacMillan, Nature 2015, 524, 330 334; b) Q.-Q. Zhou, F.-D. Lu, D. Liu, L.-Q. Lu, W.-J. Xiao, Org. Chem. Front. 2018, 5, 3098 - 3102; c) R. Sun, Y. Qin, S. Ruccolo, C. Schnedermann, C. Costentin, D. G. Nocera, J. Am. 
Chem. Soc. 2019, 141, 89 - 93; d) C. Cavedon, A. Madani, P. H. Seeberger, B. Pieber, Org. Lett. 2019, 21, 5331 - 5334; e) Y. Qin, B. C. Martindale, R. Sun, A. J. Rieth, D. G. Nocera, Chem. Sci. 2020, 11, 7456 - 7461; f) X. Zhao, C. Deng, D. Meng, H. Ji, C. Chen, W. Song, J. Zhao, ACS Catal. 2020, 10, 15178 - 15185; g) L. Yang, H.-H. Lu, C.-H. Lai, G. Li, W. Zhang, R. Cao, F. Liu, C. Wang, J. Xiao, D. Xue, Angew. Chem. Int. Ed. 2020, 59, 12714 - 12719; Angew. Chem. 2020, 132, 12814 - 12819; h) R. A. Escobar, J. W. Johannes, Chem. Eur. J. 2020, 26, 5168 - 5173.

[12] Selected examples of Ni-catalyzed $O$-arylation of alcohols with special ligands: a) P. M. MacQueen, J. P. Tassone, C. Diaz, M. Stradiotto, J. Am. Chem. Soc. 2018, 140, 5023 - 5027; b) T. Hashimoto, K. Shiota, K. Funatsu, Y. Yamaguchi, Adv. Synth. Catal. 2021, 363, 1625 1630 .

[13] An example of Ni-catalyzed $O$-arylation of alcohols with catalytic amount of $\mathrm{Zn}(0)$ : R. Sun, Y. Qin, D. G. Nocera, Angew. Chem. Int. Ed. 2020, 59, 9527 - 9533; Angew. Chem. 2020, $132,9614-9620$.

[14]a) C. Li, Y. Kawamata, H. Nakamura, J. C. Vantourout, Z. Liu, Q. Hou, D. Bao, J. T. Starr, J. Chen, M. Yan, P. S. Baran, Angew. Chem. Int. Ed. 2017, 56, 13088 - 13093; Angew. Chem. 2017, 129, 13268 - 13273. b) Y. Kawamata, J. C. Vantourout, D. P. Hickey, P. Bai, L. Chen, Q. Hou, W. Qiao, K. Barman, M. A. Edwards, A. F. Garrido-Castro, J. N. deGruyter, H. Nakamura, K. Knouse, C. Qin, K. J. Clay, D. Bao, C. Li, J. T. Starr, C. Garcia-Irizarry, N. Sach, H. S. White, M. Neurock, S. D. Minteer, P. S. Baran, J. Am. Chem. Soc. 2019, 141, 6392 $-6402$.

[15] a) P. T. Matsunaga, G. L. Hillhouse, A. L. Rheingold, J. Am. Chem. Soc. 1993, 115, 2075 2077; b) K. Koo, G. L. Hillhouse, Organometallics 1995, 14, 4421 - 4423; c) P. T. Matsunaga, J. C. Mavropoulos, G. L. Hillhouse, Polyhedron, 1995, 14, 175 - 185; d) K. Koo, G. L. Hillhouse, Organometallics 1996, 15, 2669 - 2671; e) R. Han, G. L. Hillhouse, A. L. Rheingold, J. Am. Chem. Soc. 1997, 119, 8135 - 8136; f) D. J. Mindiola, G. L. Hillhouse, J. Am. Chem. Soc. 2001, 123, 4623 - 4624; g) B. L. Lin, C. R. Clough, G. L. Hillhouse, J. Am. Chem. Soc. 2002, 124, 2890 - 2891;

[16]L. Ilies, T. Matsubara.; E. Nakamura, Org. Lett. 2012, 14, 5570 - 5573.

[17]E. B. Corcoran, M. T. Pirnot, S. Lin, S. D. Dreher, D. A.DiRocco, I. W. Davies, S. L. Buchwald, D. W. C. MacMillan, Science 2016, 353, $279-283$. 
[18]N. A. Till, L. Tian, Z. Dong, G. D. Scholes, D. W. C. MacMillan, J. Am. Chem. Soc. 2020, $142,15830-15841$.

[19]Y. Qin, R. Sun, N. P. Gianoulis, D. G. Nocera, J. Am. Chem. Soc. 2021, 143, 2005 - 2015.

[20] Selected examples of paired electrolysis: a) G. Hilt, Angew. Chem. Int. Ed. 2003, 42, 1720 1721; Angew. Chem. 2003, 115, 1760 - 1762; b) Y. Ma, X. Yao, L. Zhang, P. Ni, R. Cheng, J. Ye, Angew. Chem. Int. Ed. 2019, 58, 16548 - 16552; Angew. Chem. 2019, 131, 16700 16704; c) L. Zhang, X. Hu, Chem. Sci. 2020, 11, 10786 - 10791; d) C. Zhu, H. Yue, P. Nikolainko, M. Rueping, CCS Chem. 2020, 2, 179 - 190; e) D. Liu, Z.-R. Liu, C. Ma, K.-J. Jiao, B. Sun, L. Wei, J. Lefranc; S. Herbert; T.-S. Mei, Angew. Chem. Int. Ed. 2021, 60, 9444 - 9449; Angew. Chem. 2021, 1339530 - 9535; f) Z. Li, W. Sun, X. Wang, L. Li, Y. Zhang, C. Li, J. Am. Chem. Soc. 2021, 143, 3536-3543; g) L. Wei, Z.-H. Wang, K.-J., Jiao, D. Liu, C. Ma, P. Fang, T.-S. Mei, J. Org. Chem. 2021, DOI: 10.1021/acs.joc.1c00204. A recent perspective on paired electrolysis: h) J. C. Vantourout, Org. Process Res. Dev, 2021, DOI: 10.1021/acs.oprd.1c00046. Recent reviews on paired electrolysis: i) W. Zhang, N. Hong, L. Song, N. Fu, Chem. Rec. 2021, 21, 1 - 12; j) L. F. T. Novaes, J. Liu, Y. Shen, L. Lu, J. M. Meinhardt, S. Lin, Chem. Soc. Rev. 2021, DOI: 10.1039/D1CS00223F. 